\title{
Effect of cariogenic challenge on the stability of dentin bonds
} Fernanda Blos BORGES ${ }^{1}$, Ellen Luísa KOCHHANN DE LIMA ${ }^{1}$, Fernanda Wiengärtner MACHADO $^{1}$, Noéli BOSCATO $^{2}$,
Françoise Hélène VAN DE SANDE ${ }^{2}$, Rafael Ratto de MORAES ${ }^{2}$, Maximiliano Sérgio CENCI $^{2}$

1- School of Dentistry, Federal University of Pelotas (UFPel), Pelotas, RS, Brazil.

2- Graduate Program in Dentistry, School of Dentistry, Federal University of Pelotas (UFPel), Pelotas, RS, Brazil.

Corresponding address: Maximiliano S. Cenci - Faculdade de Odontologia - Universidade Federal de Pelotas - Rua Gonçalves Chaves, 457 - $96015-560$

- Pelotas - RS - Brazil - Phone/Fax: +55 533225.6741 - e-mail m.s.cenci@pq.cnpq.br / cencims@gmail.com

Submitted: January 9, 2013 - Modification: November 25, 2013 - Accepted: December 3, 2013

\section{ABSTRACT}

$\mathrm{O}$ bjective: The oral environment is subject to biofilm accumulation and cariogenic challenge, and few studies exist on the effect of these factors on the bond strength of adhesive systems. The aim of this study was to test if the exposure of adhesive interfaces to cariogenic challenge under biofilm accumulation could promote higher degradation than the exposure to biofilm accumulation alone. Material and Methods: Five molars were ground until exposure of medium dentin and then restored (Single Bond 2 and Z250 3M ESPE). The tooth/resin sets were cut to obtain beam-shaped specimens, which were distributed according to the aging conditions $(n=20)$ : water for $24 \mathrm{~h}$ (control); biofilm under cariogenic challenge for 3, 5 or 10 days; biofilm without cariogenic challenge for 10 days; and water for 3 months. Microcosm biofilms were formed from human saliva and grown in a saliva analogue medium, supplemented or not with sucrose to promote cariogenic challenge. Specimens were tested for microtensile bond strength, and failure modes were classified using light microscopy. Bond strength data were analyzed using ANOVA and failure modes were analyzed using ANOVA on ranks $(\alpha=0.05)$. Results: No significant differences in bond strength were detected among the aging methods $(P=0.248)$. The aging period was associated with an increase in the frequency of adhesive failures for the groups aged for 10 days or longer $(P<0.001)$. Conclusion: Aging leads to a higher prevalence of interfacial adhesive failures, although this effect is not associated with cariogenic challenge or reduction in bond strengths.

Keywords: Biofilms. Dental caries. Dentin-bonding agents.

\section{INTRODUCTION}

Secondary caries is one of the most important etiologic factors in restoration failure and the most common reason for replacing adhesive fillings, particularly in high caries risk patients ${ }^{10,26,28,32}$. However, the relationship between caries adjacent to restorations, adhesive/restoration bond strength, and marginal leakage remains relatively unexplored given the existence of few experimental and prospective studies designed to address this aspect $^{5-7,17}$.

The instability of the adhesion of restorative biomaterials to dentin has been demonstrated in vitro ${ }^{1,13-16,24,25,30}$. Degradation is known to possibly occur in the dentin substrate and/or in the polymer component of the restoratives ${ }^{3,4,13}$. Proper hybridization has been considered a key factor for obtaining durable and strong dentin bonds protected from bacteria and hydrolytic action of oral fluids.

Studies on the longevity of restorative materials bonded to tooth structures usually simulate the clinical aging of the adhesive interfaces using mechanical/thermal cycling $7,15,19,20,24$ or static protocols of water storage $1,8,9,13,14,16,20,25,33$. However, studies on the quality and longevity of bonding to dentin should be carried out simulating the actual conditions of the oral environment. Attempts to simulate the cariogenic challenge have been performed using $\mathrm{pH}$-cycling models ${ }^{18,22,23,27}$, which fail to mimic the actual in vivo conditions with 
biofilm accumulation

Considering that biofilm accumulation and cariogenic challenge are conditions to which the oral environment is exposed, and that the effect of these factors on the bond strength of adhesive systems to dentin has been seldom evaluated, this study was designed to investigate whether the cariogenic challenge would interfere with the dentin bond stability of an adhesive system. The null hypothesis is that there are no statistically significant differences in the bond strength of an adhesive system subjected to different aging protocols.

\section{MATERIAL AND METHODS}

\section{Experimental design}

In a completely randomized and blind study, microcosm dental biofilm originated from saliva of one donor was grown on resin-dentin beamshaped composite-dentin specimens in 24-well microplates using a previously described ${ }^{12}$ method adapted to promote cariogenic challenge in dentin and enamel ${ }^{2,31}$. The research protocol was approved by the local Ethics Committee (protocol 064/2008); written informed consent was obtained from the saliva donor. Biofilm was grown in a chemically defined saliva analogue with mucin (DMM)12,31 supplemented or not with sucrose according to the experimental group. The factor under evaluation was aging condition at 6 levels, as shown in Table 1 . Therefore, 6 experimental subsets were obtained and each subset comprised 20 individual resin-dentin beam-shaped specimens. Biofilm acidogenicity was determined daily through $\mathrm{pH}$ measurements of the saliva analogue supernatant. After growth media replacements, the $\mathrm{pH}$ was individually recorded from each well of the discarded plate (Quimis 50w, Quimis, Diadema, SP, Brazil; V621 electrode, Analion, Ribeirão Preto, SP, Brazil) once a day for batch (without cariogenic challenge) and twice a day for semi-continuous groups (with cariogenic challenge: one $\mathrm{pH}$ reading for the pure DMM and one reading for the DMM supplemented with sucrose).

\section{Preparation of the specimens}

The occlusal faces of five human third molars were wet-ground to create a flat surface in medium dentin. The surfaces were wet-polished with 600grit SiC papers to standardize the smear layer. The teeth were then restored using 35\% phosphoric acid (15 s), and the two-step, etch-and-rinse adhesive system Single Bond 2 (3M ESPE, St. Paul, MN, USA) was applied to dentin according to the manufacturer's instructions and then light cured for 20 s. A composite restoration was built-up on each dental surface using $2 \mathrm{~mm}$ increments of a resin composite (Filtek Z250; 3M ESPE); each increment was photoactivated for 20 s using a LED unit (Radii, SDI, Bayswater, Victoria, Australia) with 800 mW/ $\mathrm{cm}^{2}$ irradiance. After storage in distilled water at $37^{\circ} \mathrm{C}$, for $24 \mathrm{~h}$, the specimens were sectioned perpendicular to the bonded interfaces into resindentin beam-shaped specimens with a crosssectional area of approximately $0.5 \mathrm{~mm}^{2}$. For each tooth, 24 beams were obtained. The beams were separated according to tooth origin, protected with nail varnish (except the adhesive interface region) and randomly assigned into six groups $(n=20)$ according to the aging conditions. Each group had beams from every tooth proportionally distributed according to the randomization procedure.

\section{Cariogenic challenge}

Saliva was used as inoculum to provide a multispecies microcosm biofilm. Approximately 9 $\mathrm{mL}$ of stimulated saliva (Parafilm " $\mathrm{M}$ " ${ }^{\circledR}$, American National CanTM, Chicago, IL, USA) was collected from a healthy donor in the morning, $2 \mathrm{~h}$ after the last meal, and the volunteer abstained from oral hygiene $24 \mathrm{~h}$ before collection. An aliquot of 0.1 $\mathrm{mL}$ of fresh and homogenized saliva was inoculated on each specimen, except for the groups aged in distilled water. After $1 \mathrm{~h}$, the saliva was gently aspirated and growth media $(1.8 \mathrm{~mL})$ was added according to each group condition. The groups under cariogenic challenge received $1.8 \mathrm{~mL}$ DMM with $1 \%$ of sucrose (DMM+s) for $4 \mathrm{~h}$ and, after the sugar challenge, the discs were dip washed for 10 $\mathrm{s}$ in sterile saline solution and transferred to a new plate with pure DMM for $20 \mathrm{~h}$, whereas the group without cariogenic challenge received DMM for 24 h, replaced daily.

\section{Bond strength test and failure analysis}

After the experimental period of each group, the specimens were removed from the wells, cleaned, and prepared for the bond strength test. The beam-shaped specimens were subjected to a microtensile test in a mechanical testing machine (DL500, EMIC, São José dos Pinhais, PR, Brazil) at a crosshead speed of $0.5 \mathrm{~mm} / \mathrm{min}$ until failure. The cross-sectional area at the site of the fracture was measured with a digital caliper (Mitutoyo; Suzano, Brazil) with an accuracy of $0.01 \mathrm{~mm}$. The load (in Kgf) and the bonding surface area of each specimen were recorded. The microtensile bond strengths were calculated in $\mathrm{MPa}$, using the formula: $\mathrm{R}=\mathrm{F}$ (Kgf)/A (cm). Pretest failures were not included in the statistical analysis. Data were submitted to a one-way ANOVA $(P<0.05)$. After testing, the fractured specimens were carefully removed from the testing device and analyzed under optical microscopy at 100 and $500 \times$ magnifications by a blinded calibrated examiner. The modes of 
Table 1- Groups tested and results for bond strength and failure modes

\begin{tabular}{|c|c|c|}
\hline Aging condition & Bond strength, MPa* & Failure modes $(\% \mathrm{M}-\mathrm{A})^{\star *}$ \\
\hline $24 \mathrm{~h}$ in distilled water (control) & $41.0(15.6)$ & $94.8-5.2^{\mathrm{ab}}$ \\
\hline 3 days under cariogenic challenge & $35.6(16.2)$ & $95.4-4.6^{a}$ \\
\hline 5 days under cariogenic challenge & $41.7(16.3)$ & $69.3-30.7^{\mathrm{abc}}$ \\
\hline 10 days under cariogenic challenge & $33.5(12.7)$ & $42.1-57.9^{\mathrm{bcd}}$ \\
\hline 10 days without cariogenic challenge & $32.1(9.5)$ & $20-80^{\text {cd }}$ \\
\hline 3 months in distilled water & $41.1(17.7)$ & $5.9-94.1^{d}$ \\
\hline
\end{tabular}

*Means (standard deviations). No significant differences were detected among groups $(P=0.248)$

${ }^{* *}$ Percentage of mixed $(M)$ and adhesive $(A)$ failures. Distinct letters indicate significant differences $(P<0.05)$

failure were classified ${ }^{5}$ as adhesive failure (on the interface) or mixed failure (involving dentin and/or resin). Cohesive failures within dentin and prematurely debonded specimens were discarded. Failure data were submitted to a Kruskal-Wallis one-way ANOVA on ranks. All pairwise multiple comparison procedures were performed using Dunn's method $(P<0.05)$.

\section{RESULTS}

Means \pm standard deviations for $\mathrm{pH}$ throughout the experiment were $7.4 \pm 0.12$ for the group without cariogenic challenge, $7.0 \pm 0.15$ for the DMM without sucrose addition in the cariogenic challenge groups, and $4.4 \pm 0.13$ after $4 \mathrm{~h}$ exposure to DMM supplemented with sucrose in the cariogenic challenge groups. Table 1 shows the results for the bond strength test. The statistical analysis showed no significant differences among the aging conditions $(P=0.248)$. Table 1 also shows the results for the failure analysis. In contrast, the statistical analysis showed significant differences among the groups $(P<0.001)$. The aging period was associated with an increase in the frequency of adhesive failures. For the control group and the groups submitted to cariogenic challenge for 3 or 5 days, a predominance of mixed failures was detected, whereas a predominance of adhesive failures was detected for the other groups.

\section{DISCUSSION}

Previous studies showed that long-term storage in water and other aging conditions may affect the durability of the dentin bonds ${ }^{13,16,25,29}$. The breakdown of the adhesive interfaces was related to loss of stability of the polymer components of the adhesive assembly ${ }^{4,9,30}$. Polymer degradation may gradually take place because of water penetration through nano-leakage channels, resulting in lower bond strengths and interfacial failure ${ }^{25}$. Degradation of the collagen matrix from proteolytic activity of dentin intrinsic matrix metalloproteinases was also raised as one of the mechanisms for bonding breakdown ${ }^{4}$. Moreover, it was shown that cariogenic bacteria could degrade dental resin composites and adhesives ${ }^{3}$. However, in the present study, no significant differences in bond strength were observed among the groups tested, i.e., the cariogenic challenge did not promote higher degradation of the adhesive interfaces as compared with accumulation of biofilm alone or aging under water storage. Therefore, the null hypothesis tested was accepted.

Under normal conditions, human saliva meets all chemical requisites for remineralization of the dental hard tissues, and the saliva analogue medium used is supersaturated in relation to hydroxyapatite. This condition automatically facilitates the precipitation of calcium and phosphate ${ }^{21}$, which could protect the collagen network and adhesive components from further hydrolysis ${ }^{14,16}$. Moreover, the storage time under cariogenic challenge may not have been long enough to promote significant damage to the adhesive interfaces by acid penetration into the interfacial region, which could presumably affect bond strength. In fact, we simulated a low to moderate cariogenic challenge, providing short periods of demineralization followed by longer periods of remineralization, similar to what happens in the oral cavity ${ }^{12}$. To promote a higher cariogenic challenge, a sucrose exposure time in the biofilm model $\geq 6 \mathrm{~h}^{31}$ should be used, but a higher cariogenic challenge could also promote fast, unsought demineralization of the dentin tissue in the beam-shaped specimens ${ }^{2,4}$.

In contrast to the bond strength results, the failure analysis provided evidence of a detrimental effect imposed by the aging conditions on the dentin bonds. A shift from predominance of mixed failures to predominance of adhesive failures was detected for the groups aged for 3 months in water or 10 days in the biofilm model, irrespective of the exposure to cariogenic challenge. For the group stored in water for 3 months, almost all of the failure modes were adhesive, likely an effect of the water uptake leading to hydrolytic degradation of the polymer 
component. Degradation of dental crosslinked networks has been linked to mechanisms involving oxidation, attack of functional groups, and chain scission ${ }^{11}$; the extent of these processes is related to the composition of the monomers producing the network and is expected to be material-dependent. Therefore, the performance of bonding agents under cariogenic challenge may vary according to their formulation.

The present results suggest that storage conditions comprising cariogenic challenge may not promote higher degradation of the dentin adhesive interfaces than static water storage alone. However, although the bond strength test by itself was unable to detect significant differences among groups, the failure analysis provided evidence that a hydrolytic effect took place as a function of the aging time. This finding reinforces the need to associate bond strength data with failure analysis. In addition, increasing the time of cariogenic challenge or the cariogenic challenge by using longer demineralization periods would be a valid approach, although these conditions could potentially increase the frequency of premature debonding or occurrence of cohesive failures within the bonding substrate attributable to the extended mineral loss ${ }^{4}$. Nevertheless, in situ aging of beamshaped specimens could present the possibility for further assessing the effects that the condition state in an oral environment may have on dentin bond stability.

The conditions of the present in vitro study took into account the effects that the demineralization and remineralization processes may have in the oral cavity, and this model could be used to reproduce the clinical aging conditions for adhesive interfaces. Similar models have been used in the literature to test hypothesis related to materials with antimicrobial activity ${ }^{33,34}$, development of secondary caries $^{6}$, and other phenomena ${ }^{2,31}$. Nonetheless, it is important to acknowledge that in vitro studies have limitations because they cannot simulate all the complexity of an in vivo environment, such as exposure to food intake and salivary flow. Additionally, it is important to note that the aging processes in the present study were applied to beam-shaped specimens to allow comparisons with previous studies, which have also aged beam-shaped specimens. Inducing aging in these specimens with reduced dimensions would accelerate the degradation process, reducing the length of the experiment, which is an advantage for in vitro biofilm models. However, future studies should be carried out aging in vitro or in situ restorations where dentin is surrounded by enamel for longer periods, in order to truly simulate the clinical conditions present in the mouth.

\section{CONCLUSION}

Aging of dentin bonds leads to a higher prevalence of adhesive failures, although this effect may not be associated with a cariogenic challenge or a reduction in bond strengths.

\section{REFERENCES}

1- Abdalla AI, Feilzer AJ. Two-year water degradation of selfetching adhesives bonded to bur ground enamel. Oper Dent. 2009;34:732-40.

2- Azevedo MS, van de Sande FH, Romano AR, Cenci MS. Microcosm biofilms originating from children with different caries experience have similar cariogenicity under successive sucrose challenges. Caries Res. 2011;45:510-7.

3- Bourbia M, Ma D, Cvitkovitch DG, Santerre JP, Finer Y. Cariogenic bacteria degrade dental resin composites and adhesives. J Dent Res. 2013;92:989-94.

4- Breschi L, Martin P, Mazzoni A, Nato F, Carrilho M, Tjäderhane $L$, et al. Use of a specific MMP-inhibitor (galardin) for preservation of hybrid layer. Dent Mater. 2010;26:571-8.

5- Cenci M, Demarco F, Carvalho R. Class II composite resin restorations with two polymerization techniques: relationship between microtensile bond strength and marginal leakage. J Dent. 2005;33:603-10.

6- Cenci MS, Pereira-Cenci T, Cury JA, Ten Cate JM. Relationship between gap size and dentine secondary caries formation assessed in a microcosm biofilm model. Caries Res. 2009;43:97-102.

7- Cenci MS, Pereira-Cenci T, Donassollo TA, Sommer L, Strapasson

$A$, Demarco FF. Influence of thermal stress on marginal integrity of restorative materials. J Appl Oral Sci. 2008;16:106-10.

8- De Munck J, Van den Steen PE, Mine A, Van Landuyt KL, Poitevin $A$, Opdenakker $G$, et al. Inhibition of enzymatic degradation of adhesive-dentin interfaces. J Dent Res. 2009;88:1101-6.

9- De Munck J, Van Landuyt K, Peumans M, Poitevin A, Lambrechts $P$, Braem $M$, et al. A critical review of the durability of adhesion to tooth tissue: methods and results. J Dent Res. 2005;84:118-32. 10- Demarco FF, Corrêa MB, Cenci MS, Moraes RR, Opdam NJ. Longevity of posterior composite restorations: not only a matter of materials. Dent Mater. 2012;28:87-101.

11- Ferracane JL. Hygroscopic and hydrolytic effects in dental polymer networks. Dent Mater. 2006;22:211-22.

12- Filoche SK, Soma KJ, Sissons CH. Caries-related plaque microcosm biofilms developed in microplates. Oral Microbiol Immunol. 2007;22:73-9.

13- Fontes ST, Lima GS, Ogliari FA, Piva E, Moraes RR. Hybridization morphology and dentin bond stability of self-etch primers with different ethanol/water ratios. Odontology. 2012;100:181-6.

14- Gamborgi GP, Loguercio AD, Reis A. Influence of enamel border and regional variability on durability of resin-dentin bonds. J Dent. 2007;35:371-6.

15- Gonçalves LS, Consani S, Sinhoreti MA, Schneider LF, Saboia VP. Effect of storage and compressive cycles on the bond strength after collagen removal. Oper Dent. 2009;34:681-7.

16- Hashimoto M, Fujita S, Nagano F, Ohno H, Endo K. Ten-years degradation of resin-dentin bonds. Eur J Oral Sci. 2010;118:40410.

17- Heintze SD. Systematic reviews: I. The correlation between laboratory tests on marginal quality and bond strength. II. The correlation between marginal quality and clinical outcome. J Adhes Dent. 2007;9:77-106.

18- Kantovitz KR, Pascon FM, Alves MC, Nociti FH, Tabchoury CP, Puppin-Rontani RM. Influence of different enamel substrates on microtensile bond strength of sealants after cariogenic challenge. J Adhes Dent. 2011;13:131-7. 
19- Lodovici E, Reis A, Geraldeli S, Ferracane JL, Ballester RY, Rodrigues Filho LE. Does adhesive thickness affect resin-dentin bond strength after thermal/load cycling? Oper Dent. 2009;34:5864.

20- Mair L, Padipatvuthikul P. Variables related to materials and preparing for bond strength testing irrespective of the test protocol. Dent Mater. 2010;26:e17-23.

21- Mäkinen KK. Sugar alcohols, caries incidence, and remineralization of caries lesions: a literature review. Int J Dent. 2010;2010:981072.

22- Marquezan M, Osorio R, Ciamponi AL, Toledano M. Resistance to degradation of bonded restorations to simulated caries-affected primary dentin. Am J Dent. 2010;23:47-52.

23- Marquezan M, Skupien JA, Silveira BL, Ciamponi A. Nanoleakage related to bond strength in RM-GIC and adhesive restorations. Eur Arch Paediatr Dent. 2011;12:15-21.

24- Mitsui FH, Peris AR, Cavalcanti AN, Marchi GM, Pimenta LA. Influence of thermal and mechanical load cycling on microtensile bond strengths of total and self-etching adhesive systems. Oper Dent. 2006;31:240-7.

25- Okuda M, Pereira PN, Nakajima M, Tagami J, Pashley DH. Long-term durability of resin dentin interface: nanoleakage vs. microtensile bond strength. Oper Dent. 2002;27:289-96.

26- Opdam NJ, Bronkhorst EM, Loomans BA, Huysmans MC. Longevity of repaired restorations: a practice based study. J Dent. 2012;40:829-35.

27- Passalini P, Fidalgo TK, Caldeira EM, Gleiser R, Nojima MC, Maia LC. Mechanical properties of one and two-step fluoridated orthodontic resins submitted to different $\mathrm{pH}$ cycling regimes. Braz Oral Res. 2010;24:197-203.
28- Roumanas ED. The frequency of replacement of dental restorations may vary based on a number of variables, including type of material, size of the restoration, and caries risk of the patient. J Evid Based Dent Pract. 2010;10:23-4.

29- Shono Y, Terashita M, Shimada J, Kozono Y, Carvalho RM, Russell CM, et al. Durability of resin-dentin bonds. J Adhes Dent. 1999; $1: 211-8$.

30- Tay FR, Pashley DH, Suh BI, Carvalho RM, Itthagarun A. Single-step adhesives are permeable membranes. J Dent. 2002;30:371-82.

31- Van de Sande FH, Azevedo MS, Lund RG, Huysmans MC, Cenci MS. An in vitro biofilm model for enamel demineralization and antimicrobial dose-response studies. Biofouling. 2011;27:105763.

32- Van de Sande FH, Opdam NJ, Rodolpho PA, Correa MB, Demarco FF, Cenci MS. Patient risk factors' influence on survival of posterior composites. J Dent Res. 2013;92:78S-83S.

33- Zhang K, Cheng L, Wu EJ, Weir MD, Bai Y, Xu HH. Effect of water-ageing on dentine bond strength and anti-biofilm activity of bonding agent containing new monomer dimethylaminododecyl methacrylate. J Dent. 2013;41:504-13.

34- Zhou H, Li F, Weir MD, Xu HH. Dental plaque microcosm response to bonding agents containing quaternary ammonium methacrylates with different chain lengths and charge densities. J Dent. 2013;41:1122-31. 